\title{
Dosis única de ciclofosfamida disminuye la calidad espermática y el epitelio germinal masculino en ratones
}

\author{
Unique cyclophosphamide doses in male mice decrease the spermatic \\ quality and germinal epithelium
}

\author{
Láyonal Acosta ${ }^{1,3 *}$, Víctor Núñez ${ }^{1,3}$, Jonathan Vásquez $^{1,2}$, José Pino $^{1}$ y Betty Shiga ${ }^{1}$
}

1 Laboratorio de Reproducción y Biología del Desarrollo, Departamento de Zoología. Facultad de Ciencias Biológicas. Universidad Nacional Mayor de San Marcos (UNMSM). Lima, Perú. Av. Vene(UnMSM). Lima, Perú. Av. Vene5116197000 ext. Penú Tel. +511 6197000 extensión 1529. fax: +511 4649110. PO BOX 11 0058. Lima 11

2 Laboratorio de Fisiología de la Reproducción Animal. Instituto de Reducción Animal. Instifuto de Investigación en Ciencias Biológicas "Antonio Raimond", Facultad de Ciencias Biológicas, UNMSM Lima, Perú.

3 REPROLAB PERÚ SAC. LIma - Perú.

* Autor para correspondencia: Email Láyonal Acosta: acostaclg@gmail.com

Presentado: $\quad$ 08/02/2012 Aceptado: 20/09/2012 Publicado online: 10/11/2012

\section{Resumen}

Ciclofosfamida (CP) es un agente alquilante comúnmente utilizado como fármaco antineoplásico e inmunosupresor. El uso de CP, en el tratamiento de cáncer es limitado debido a su severa toxicidad. El objetivo de presente estudio fue determinar el efecto de una única dosis de CP (220 mg/kg peso corporal) administrada intraperitonealmente después de 7 días, sobre parámetros espermáticos y el epitelio germinal masculino en ratones. Se utilizó machos maduros de la cepa C57BL divididos en 2 grupos ( $n=10)$, Grupo Control (C): NaC 0,9\% y Grupo Tratamiento (T): CP a $220 \mathrm{mg} / \mathrm{kg}$ pc en dosis única y después de 8 días fueron eutanizados. Se registró el peso corporal y de órganos reproductivos: testículos, epidídimos y conducto deferente, se evaluaron la concentración, movilidad y morfología espermática e histología testicular. Se encontraron diferencias significativas (Prueba t- student $p<0,05$ ) en el peso corporal (T: 20,18 $\pm 1,9 \mathrm{~g}$ vs C: $23,35 \pm 1,2 \mathrm{~g}$ ); peso testicular (T: $59,71 \pm 5,40 \mathrm{mg}$ vs C: $72,90 \pm 2,8 \mathrm{mg}$ ), cola del epidídimo (T: $9,83 \pm 1,54 \mathrm{mg}$ vs C: $14,30 \pm 2,20 \mathrm{mg}$, conducto

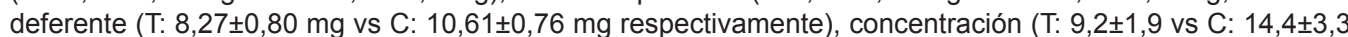
x $10^{6}$ espermatozoides $/ \mathrm{mL}$ ), Movilidad progresiva (T: $25,98 \pm 6,4 \%$ vs C: $42,96 \pm 5,2 \%$ ). En la morfología espermática no se observó diferencias significativas (Prueba t- student $p<0,05$ ), sin embargo en anomalías de la cola y espermatozoides inmaduros se observó un aumento significativo (T vs. C: $36,24 \pm 7,8 \%$ vs $31.73 \pm 9,1 \%$; $27,44 \pm 2,1 \%$ vs $18,51 \pm 8,6 \%$; respectivamente) y a su vez se observó severos daños en los túbulos seminíferos. Concluimos que una dosis única de CP (220mg/kg pc) disminuye la calidad reproductiva de ratones macho.

Palabras clave: Ciclofosfamida; ratón C57BL; toxicidad; fertilidad; análisis seminal.

\section{Abstract}

Cyclophosphamide (CP) is an alkylating agent commonly used as antineoplastic and immunosuppressive drug. The use of CP in the treatment of cancer is limited due to its severe toxicity. The aim of this study was to determine theeffectof a single dose of CP $(220 \mathrm{mg} / \mathrm{kg} \mathrm{b.w.})$ intraperitoneally administered after 7 days,on sperm parameter and male germinal epithelium in mice. We used C57BL mature male mice divided into 2 groups $(\mathrm{n}=$ 10); Control Group (C): $0.9 \%$ and $\mathrm{NaCl}$ Treatment group (T): $\mathrm{CP}$ to $220 \mathrm{mg} / \mathrm{kg} \mathrm{cw}$ in single dose. After 8 days all the mice were euthanized. The weight of the body and reproductive organs: testis, epididymis and vas deferens, were registered. Concentration, motility and sperm morphology and testicular histology were evaluated. Significant differences were found in body weight (student t-test $p<0.05)$ (T: $20.18 \pm 1.9 \mathrm{~g}$ vs C: $23.35 \pm 1.2 \mathrm{~g}$; testicular weight (T: $59.71 \pm 5.40 \mathrm{mg}$ vs $\mathrm{C}: 72.90 \pm 2.8 \mathrm{mg}$ ), epididymis tail weight (T: $9.83 \pm 1.54$ vs C: $14.30 \pm$ 2.20 , vas deferens weight (T: $8.27 \pm 0.80 \mathrm{mg}$ vs $\mathrm{C}: 10.61 \pm 0.76 \mathrm{mg}$ respectively), concentration (T: $9.2 \pm 1.9 \mathrm{vs}$. C: $14.4 \pm 3.3 \times 10^{6}$ sperm / mL), progressive motility (T: $25.98 \pm 6,4 \%$ vs C: $42.96 \pm 5.2 \%$ ). There wasn't significant differences in sperm morphology (student t-test $p<0.05$ ), but there was a significant increase in abnormal tail and immature sperm (T vs. C: $36,24 \pm 7,8 \%$ vs $31.73 \pm 9,1 \% ; 27,44 \pm 2,1 \%$ vs $18,51 \pm 8,6 \%$; respectively) and also severe damage seminiferous tubules was observed. We conclude that single dose of CP $(220 \mathrm{mg} / \mathrm{kg}$ b.w.) decreased the reproductive quality of male mice.

Keywords: Cyclophosphamide; C57BL mouse; toxicity; fertility; semen analysis.

\section{Introducción}

Ciclofosfamida (CP) [N, N-bis (2-cloroetil) tetrahidro-2H-1, 3,2 oxaza - fosforin-2-amino 2-oxido] es un agente alquilante comúnmente utilizado como fármaco antineoplásico e inmunosupresor. La citotoxicidad de la CP es mediada por la alquilación del $\mathrm{ADN}$ en la posición N7 de guanina y la formación de cross-links del tipo ADN-ADN y ADN-proteína, así como quiebres en una de las hebras del ADN (Hemminki \& Kallama 1986, Crook et al. 1986).

La ciclofosfamida afecta células en división; por ejemplo, genera apoptosis celular en la línea espermática (Crook et al. 1986, Chowdhury 1987, Brinkworth \& Nieschlag 2000) e interfiere con las actividades mitóticas y meióticas de la hilera germinal. Su mecanismo de acción consiste en alquilar el ADN alterando la estructura de los ácidos nucleicos, por lo tanto la división celular no se realiza adecuadamente (Elangovan et al. 2006). En el testículo, CP interrumpe la meiosis antes de la etapa de paquiteno, produciendo daño genotóxico (Barton et al. 2003). Cuando los alquilantes se utilizan en bajas dosis, la recuperación de la espermatogénesis podría ocurrir dentro de los 3 años post-tratamiento; sin embargo, a altas dosis la infertilidad podría prolongarse o incluso ser permanente.

Pacientes varones con cáncer tratados con CP presentan una mayor incidencia de oligozoospermia y azoospermia (Charak et al. 1990, Kenney et al. 2001), además se ha demostrado perturbaciones en la secreción de gonadotropinas, daño testicular y bajos niveles de testosterona en la sangre (Hoorweg-Nijman et al. 1992). 
La inyección única de CP durante la formación de espermatocitos de ratón resulta en la aparición de translocaciones heredables (Sotomayor \& Cumming 1975) e incrementa la incidencia de micronúcleos (Tates 1992, Lahdetie 1983, 1988). El estudio morfométrico en las diferentes fases del ciclo espermatogénico indica que la toxicidad en el testículo puede ser detectada a partir de los 7 días después de una administración única de CP (100 mg/kg pc) en ratas (Matsui et al. 1995). Estudios en ratas y ratones han confirmado que $\mathrm{CP}$ en dosis única semanal durante 5 semanas disminuye el peso testicular, la concentración espermática y produce oligozoospermia transitoria (Elangovan et al. 2006).

El estudio de los efectos de CP es muy importante debido a su amplio uso en quimioterapias y a sus efectos secundarios no deseados asociados con periodos variables de infertilidad (Trasler et al. 1988). El objetivo del presente estudio fue determinar el efecto después de 7 días de sólo una dosis de CP (220mg/kg pc) administrada intraperitonealmente sobre la calidad espermática y el epitelio germinal masculino en ratones.

\section{Materiales y métodos}

Animales.- Se emplearon ratones (Mus musculus) de la cepa C57BL, machos $(\mathrm{N}=20)$ de 8 a 10 semanas de edad con peso promedio de $21,7 \pm 1,9 \mathrm{~g}$, provenientes del Bioterio del Laboratorio de Reproducción y Biología del Desarrollo, Facultad de Ciencias Biológicas de la Universidad Nacional Mayor de San Marcos. Los animales fueron mantenidos bajo condiciones estándar de bioterio $\left(24-27^{\circ} \mathrm{C}\right.$ de temperatura, fotoperíodo de $14 \mathrm{~h}$ luz: $10 \mathrm{~h}$ oscuridad) y alimentados con dieta balanceada para animales (Purina - Perú) y agua ad libitum.

Diseńo experimental.- Los ratones fueron divididos en dos grupos: el grupo Tratamiento $(\mathrm{T})(\mathrm{n}=10)$, recibió intraperitonealmente (ip) una dosis de Ciclofosfamida (NEOPHOS - Lima) de $220 \mathrm{mg} / \mathrm{kg}$ [dosis equivalente a la terapéutica en humanos $(750 \mathrm{mg} / \mathrm{kg})$ ] (Elangovan et al. 2006) y el grupo Control (C) $(n=10)$, que recibió ip una dosis de solución salina $0,9 \%$.

Al octavo día después del tratamiento se registró el peso corporal y los animales fueron eutanizados por dislocación cervical. Se pesaron: testículos, epidídimos y conductos deferentes. Se obtuvieron espermatozoides de la cola del epidídimo para registrar la movilidad, concentración y morfología espermática. Los testículos fueron separados para histología.

Obtención de epidídimos y espermatozoides.- Cada uno de los epidídimos obtenidos fueron lavados con tampón fosfato salino (PBS pH 7,4) a $37^{\circ} \mathrm{C}$, se realizaron varios cortes en la cola del epidídimo y luego los espermatozoides se liberaron, permaneciendo durante 10 minutos en $0,5 \mathrm{ml}$ de cultivo Flushing (MediCult ${ }^{\oplus}$, Copenhagen, Dinamarca), el contenido espermático se recuperó en su totalidad en tubos de polipropileno de 1,5 mL (Axygen Scientific).

Evaluación de la movilidad espermática.- Una muestra espermática fue colocada sobre una lámina portaobjetos que se encontraba a $37^{\circ} \mathrm{C}$ y observada a $400 \mathrm{X}$ en un microscopio óptico de contraste de fases (Carl Zeitz Jena, San Francisco, U.S.A). Este procedimiento fue repetido 2 veces, los resultados presentados son el promedio de ambas evaluaciones, siendo evaluados al menos 100 espermatozoides. Se consideró que un espermatozoide presentaba Movilidad Progresiva (MP), cuando presentaba desplazamiento, Movilidad No Progresiva (MNP) a aquellos que no se desplazaban y sólo tenían un movimiento in situ e Inmóviles (I) los que no presentaban ningún tipo de movimiento (WHO 2010).

Medición de concentración espermática.- La concentración espermática se midió usando una dilución $1: 20,10 \mu \mathrm{L}$ de la muestra se diluyó con $190 \mu \mathrm{L}$ de solución fijadora (WHO 2010), posteriormente se colocó $10 \mu \mathrm{L}$ del diluido en una cámara de Neubauer, y se contaron los espermatozoides dentro de los campos definidos en la cámara (5 cuadrantes), mediante el uso de un microscopio óptico de campo claro a 400X; la cantidad de espermatozoides observados se multiplicó por el factor correspondiente $\left(10^{6}\right)$. La concentración de espermatozoides fue expresada en millones/ $\mu \mathrm{L}$.

Evaluación de la morfología espermática.- Los espermatozoides fueron expandidos mediante un frotis sobre láminas portaobjetos se dejó secar a temperatura ambiente, se fijaron con paraformaldehído por 20 minutos y se colorearon con Eosina-Y al 5\%. Por individuo fueron visualizados y analizados 250 espermatozoides bajo un microscopio óptico de campo claro con objetivo de inmersión (100X). Se consideró como anormal, aquel espermatozoide que presentaba alteraciones morfológicas en cabeza, pieza intemedia, cola o en presencia de más de una alteración. Espermatozoides con gota citoplasmática fueron considerados inmaduros.

Histología.- Para el estudio histológico, ambos testículos fueron trozados y fijados en Bouin alcohólico por 16 horas, posteriormente fueron lavados y deshidratados en una batería de alcoholes e incluidos en Paraplast ${ }^{\oplus}$. Se realizaron cortes seriados de $6 \mu \mathrm{m}$, los cuales fueron coloreados con Hematoxilina Eosina-Y. La observación se realizó mediante un microscopio de campo claro (Carl Zeiss Jena). Las fotomicrografías se tomaron con una cámara digital.

Análisis estadístico.- Los resultados fueron evaluados usando el paquete estadístico SPSS 17,0 para Windows. Se realizó el test de Shapiro Wilk y Leneve para comprobar normalidad y homocedasticidad de los datos. Las diferencias entre los grupos se analizaron mediante la prueba t-Student. Los resultados son expresados como media $\pm \mathrm{EE}$ (error estándar), $\mathrm{n}=10$. Un valor de $\mathrm{p}<0,05$ fue considerado estadísticamente significativo.

\section{Resultados}

Peso corporal y órganos reproductivos.- Se encontró diferencias significativas entre el peso corporal y los órganos reproductivos evaluados (testículo, epidídimo y conducto deferente). Los resultados se resumen en la Tabla 1.

Movilidad y concentración espermática.- La concentración espermática disminuyó significativamente en el grupo T $(\mathrm{p}<0,05)$ (Tabla 2). En la movilidad se observa una diferencia significativa $(\mathrm{p}<0,05)$ en los espermatozoides con movilidad progresiva (MP) e inmoviles (I) del grupo $\mathrm{T}$ con respecto al control $(25,98 \pm 6,4$ vs $42,96 \pm 5,2$ y $50,87 \pm 6,3$ vs $36,05 \pm 4,9$, respectivamente).No se observó diferencias significativas $(\mathrm{p}<0,05)$ en los espermatozoides con movilidad no progresiva (MNP) (T: 26,68 $\pm 1,8$ vs C: $25,38 \pm 4,3$ ) (Fig. 1).

Morfología.- Las evaluaciones morfológicas no mostraron diferencias significativas (prueba t-Student, corrección arco seno, $p>0,05)$ en el porcentaje de espermatozoides normales entre el grupo $\mathrm{T}$ y el grupo C (Tabla 2). Al evaluar la distribución de 
Tabla 1. Efecto de la CP sobre el peso corporal, peso de testículo, epidídimo y conducto deferente entre el grupo Control (C) y Tratamiento (T). pc: peso corporal.

\begin{tabular}{lcc}
\hline & Control (Na Cl 0,9\%) & Ciclofosfamida (220 mg/kg pc) \\
\hline Ratones examinados & 10 & 10 \\
Peso corporal inicial (g) & $21,40 \pm 0,7$ & $21,90 \pm 1,0$ \\
Peso corporal final (g) & $23,35 \pm 1,2$ & $20,18 \pm 1,9^{*}$ \\
Peso del testículo (mg) & $72,90 \pm 2,8$ & $59,71 \pm 5.40^{*}$ \\
Peso cabeza + cuerpo del epidídimo (mg) & $19,25 \pm 0.9$ & $16,96 \pm 0.7^{*}$ \\
Peso de la cola del epidídimo (mg) & $14,30 \pm 2,20$ & $9,83 \pm 1,54^{*}$ \\
Peso del conducto deferente (mg) & $10,61 \pm 0,76$ & $8,27 \pm 0,80^{*}$ \\
\hline
\end{tabular}

Los valores son expresados como media \pm SD.

${ }^{*} \mathrm{P}<0.05$ en comparación con el grupo control.

Tabla 2. Efecto de la CP a una sola dosis sobre la concentración y Morfología espermática. pc: peso corporal

\begin{tabular}{|c|c|c|}
\hline & $\begin{array}{c}\text { Control } \\
(\mathrm{Na} \mathrm{Cl} \mathrm{0,9 \% )}\end{array}$ & $\begin{array}{l}\text { Ciclofosfamida } \\
\text { (220 mg/kg pc) }\end{array}$ \\
\hline $\mathrm{N}^{\circ}$ de ratones examinados & 10 & 10 \\
\hline $\begin{array}{c}\text { Concentración } \\
\text { espermática }\left(\times 10^{6} / \mathrm{mL}\right)\end{array}$ & $14,40 \pm 3,3$ & $9,2 \pm 1,9^{*}$ \\
\hline Morfología Normal (\%) & $39,72 \pm 1,3$ & $38,12 \pm 4,5$ \\
\hline Morfología Anormal (\%) & $60,28 \pm 1,3$ & $61,88 \pm 4,5$ \\
\hline
\end{tabular}

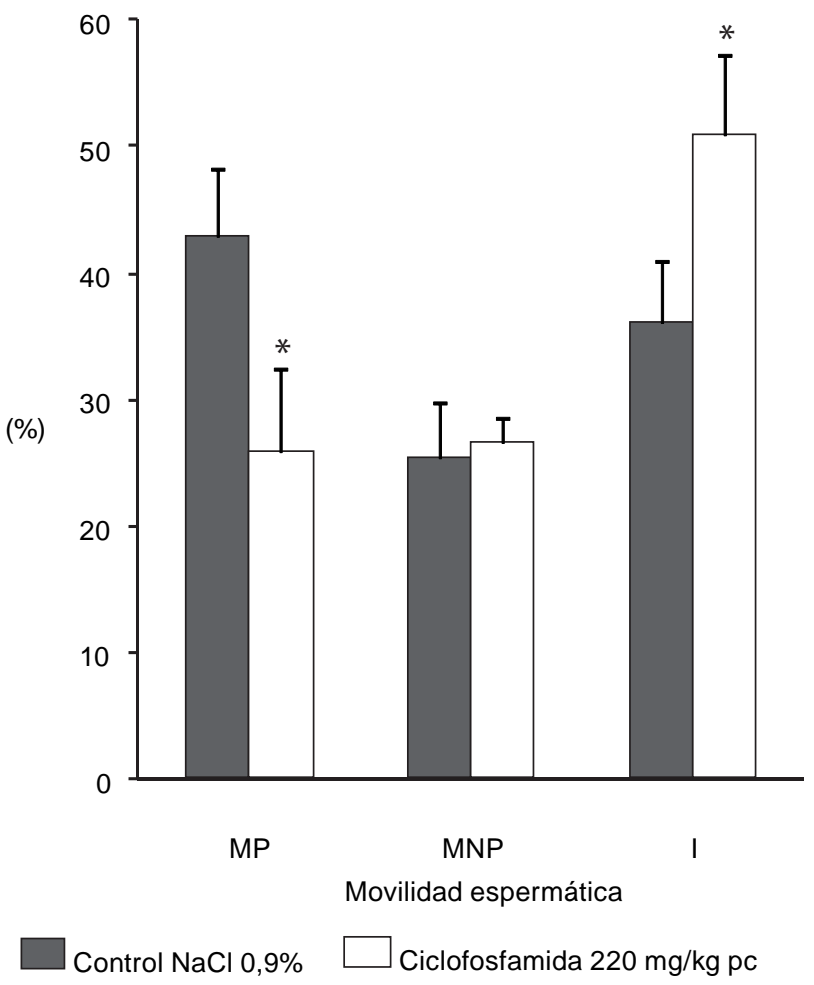

Figura 1. Efecto de la CP a una sola dosis sobre la movilidad espermática. MP: Movilidad progresiva; MNP: Movilidad no progresiva; I: Inmovilidad. pc: peso corporal. Los valores son expresados como media $\pm \mathrm{SD}$. ${ }^{\star} \mathrm{P}<0,05$ en comparación con el grupo control. anormalidades (cantidad neta de ocurrencias por cada anormalidad observada) se observó un aumento significativo $(\mathrm{p}<0,05)$, dentro de la fracción anormal, de espermatozoides inmaduros (gota citoplasmática) (T: 27,44 $\pm 2,1$ vs C: $18,51 \pm 8,6$ ) y anormalidades de la cola (T: $36,24 \pm 7,8$ vs $31.73 \pm 9,1)$. No se observó diferencias significativas $(\mathrm{p}<0,05)$ en los espermatozoides con anormalidades de la cabeza (T: $23,48 \pm 6,2$ vs C: $23,91 \pm 5,9$ ) y anormalidades de la pieza intermedia (T: $46,19 \pm 6,8$ vs C:

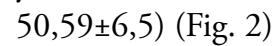

Análisis Histológico.- Se observó una severa alteración morfológica producida en los túbulos seminíferos de ratones tratados con ciclofosfamida $220 \mathrm{mg} / \mathrm{kg}$ por peso corporal, entre estas alteraciones se puede mencionar una reducción en el diámetro del túbulo seminífero (Fig. 3A), pérdida parcial del tejido intersticial y en el número de células espermatogoniales (Fig. 3C) con respecto a los controles (Figs. 3B, 3D).

\section{Discusión}

El presente estudio evaluó si una sola dosis de CP (220 mg/ $\mathrm{kg}$ pc) produce algún efecto negativo sobre la fisiología repro-

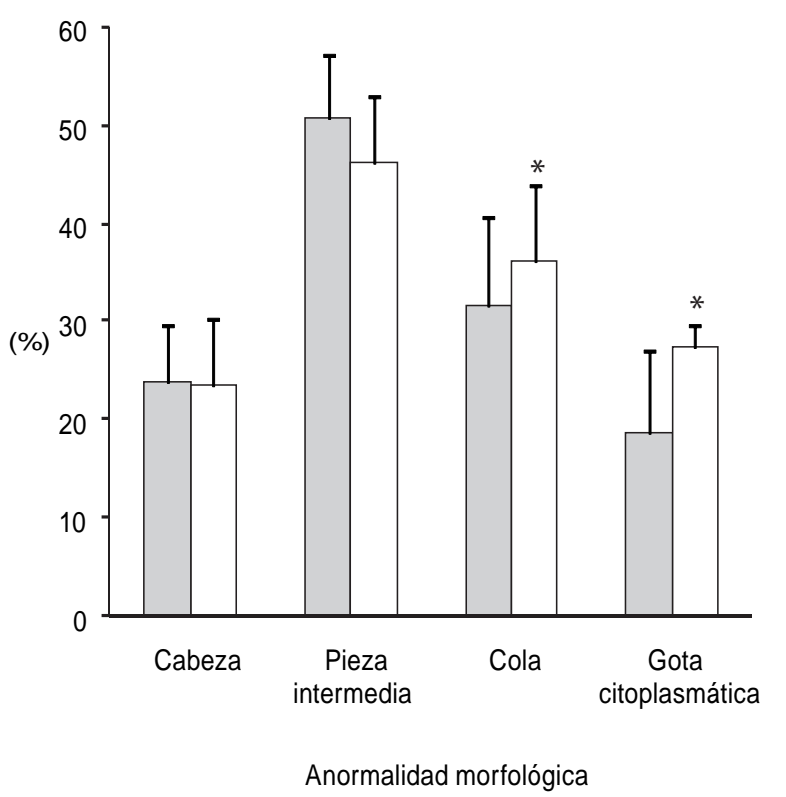

Control NaCl 0,9\% $\square$ Ciclofosfamida $220 \mathrm{mg} / \mathrm{kg} \mathrm{pc}$

Figura 2. Efecto de la CP a una sola dosis sobre los diferentes tipos de anormalidades morfológicas del espermatozoide. pc: peso corporal. Los valores son expresados como media \pm SD. * $P<0.05$ en comparación con el grupo control. 

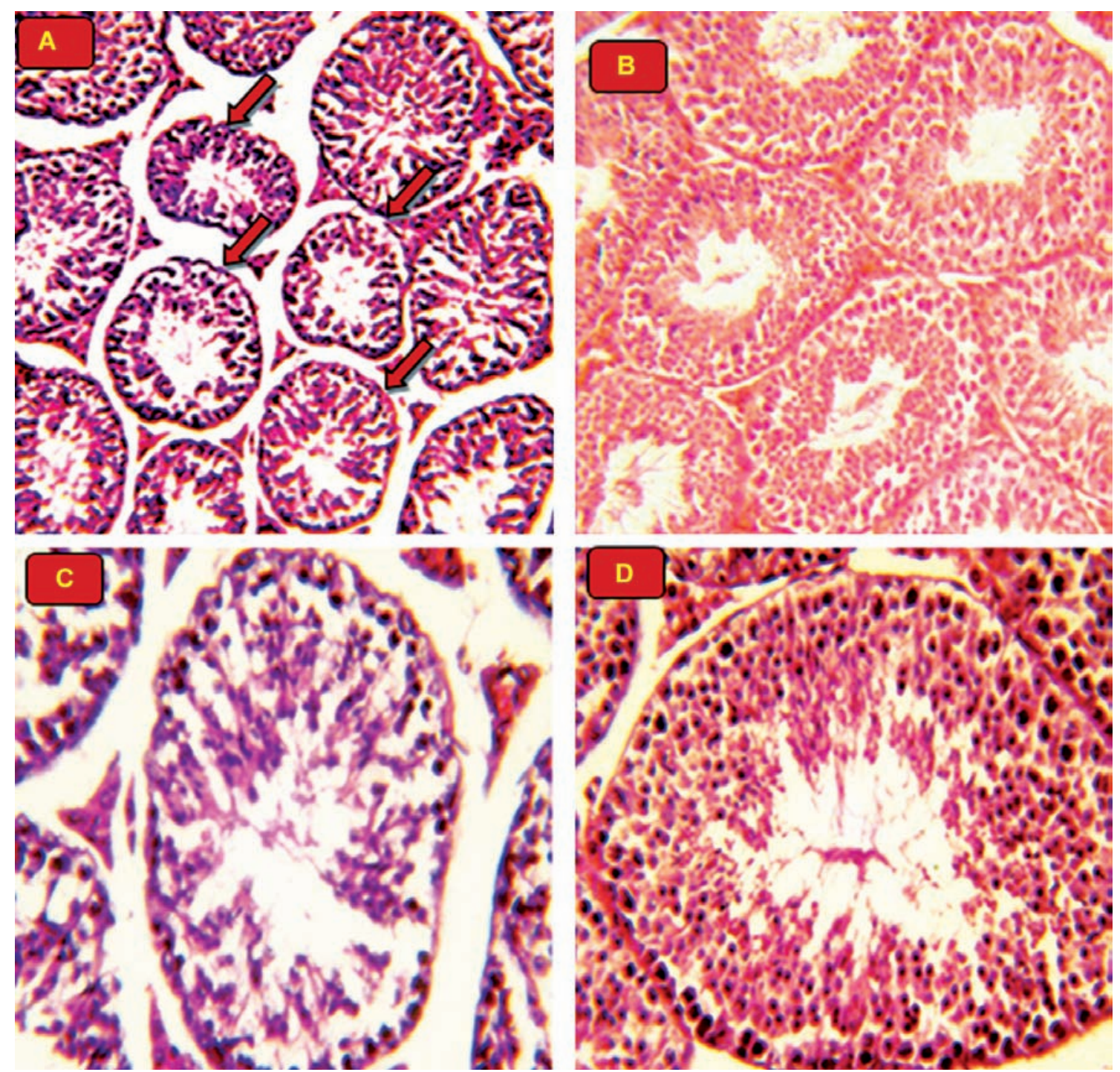

Figura 3. Túbulos seminíferos de ratón BalbC57 tratados con CP $(220 \mathrm{mg} / \mathrm{kg} \mathrm{pc})$ a una sola dosis: A (100X) y C (630X); Controles: B (100X) y D (630X). Note la disminución del tamaño de los túbulos (flecha).

ductiva, espermiación y permanencia del espermatozoide en el epidídimo. Trasler et al. (1986) y Brinkwort y Nieschlag (2000) utilizaron dosis de CP $(5,1 \mathrm{mg} / \mathrm{kg}$ pc $)$ por 9 y 11 semanas respectivamente y Da et al. (2002) proporcionó $5,0 \mathrm{mg} / \mathrm{kg} \mathrm{pc}$ por 28 días, sin observar modificaciones significativas respecto a los pesos corporales y los pesos de órganos reproductivos como testículos y epidídimos; sin embargo, Elangovan et al. (2006) inyectó una dosis más alta de CP $(200 \mathrm{mg} / \mathrm{kg}$ pc) y observó después de 7 días una disminución del peso corporal y pesos de los testículos y epidídimos, concordando con los resultados reportados en este trabajo inyectando una sola dosis de CP $(220 \mathrm{mg} / \mathrm{kg} \mathrm{pc}$ ) y evaluado al octavo día (Tabla $1, \mathrm{p}<0,05)$.

La disminución de los pesos corporales con una dosis alta $(\mathrm{CP} \geq 200 \mathrm{mg} / \mathrm{kg})$ nos sugiere existiría un efecto sistémico en el individuo y que dosis menores durante tiempos prolongados (Trasler et al. 1986, Brinkwort \& Nieschlag 2000) serían más adecuadas en los tratamientos antineoplásicos con CP. Los testículos, epidídimos y próstata son órganos dependientes de andrógenos (Trentacose et al. 2001). Cuando administramos una dosis única de CP $(220 \mathrm{mg} / \mathrm{kg} \mathrm{pc})$ observamos una disminución significativa en los pesos de los testículos y epidídimos por lo que concluimos que una inyección de $\mathrm{CP}$ a alta dosis estaría ejerciendo actividad antiandrogénica a nivel gonadal o a nivel del eje hipotálamo-hipófisis, resultados observados también con dosis menores continuas (Poblador et al. 1990, Elangovan 2006, Resvanfar et al. 2008). El peso de los testículos depende de la masa de las células madres espermatogénicas (Katoh et al. 2002), por lo que CP (220 mg/kg pc) estaría ejerciendo daño sobre las mismas (Fig. 3).

La espermatogénesis es un proceso altamente sincronizado y dinámico que se lleva a cabo en los túbulos seminíferos, en los ratones este ciclo tiene una duración de 35 días (Oakberg 1956). El tiempo de evaluación post CP en este estudio (7 días) indica su acción sobre la espermiación y el transporte en el epidídimo (Piña-Guzmán et al. 2004). La inyección única de $\mathrm{CP}$ ejerce efectos anti reproductivos, disminuyendo los valores de movilidad y concentración espermática. La disminución de la MP y el aumento de los espermatozoides inmóviles observados (Fig. 1) nos permite sugerir que $\mathrm{CP}$ podría estar impidiendo la secreción de factores proteicos en el epidídimo cuya función es completar la maduración de los espermatozoides (Bedford 1979). 
No se observó aumento en la cantidad neta de espermatozoides anormales (Tabla $2, \mathrm{p}<0,05$ ) en consecuencia del breve periodo de evaluación de los espermatozoides post-inyección de CP (7 días), de esta manera se explica porqué la administración de $\mathrm{CP}$ con dosis de $6 \mathrm{mg} / \mathrm{kg}$ pc por 28 días (Resvanfar et al. 2008) y $50 \mathrm{mg} / \mathrm{kg}$ pc por 35 dias (Arencibia et al. 2009, Valiente et al. 2010) si incrementan el porcentaje de espermatozoides con formas anormales. Sin embargo, observamos mayor cantidad de espermatozoides con presencia de gota citoplasmatica, indicio de inmadurez del espermatozoide (Fig. 2), fenómeno observado en fuerte concordancia con el tiempo de evaluación que abarca la etapa de espermiación. El estres oxidativo inducido por CP se traduce en el aumento de celulasapoptoticas (Elangovan et al. 2006), este factor y el daño al ADN durante el transito en el epidídimo pueden ser los responsables del incremento en el porcentaje de espermatozoides inmaduros.

La concentración espermática presenta una relación directa con la disminución del peso testicular (Katoch et al. 2002) y la apoptosis de las espermatogonias por acción de la $\mathrm{CP}$ disminuye el número de espermatozoides (Brinkwort \& Nieschlag 2000) siendo esto confirmado en nuestro análisis histológico (Fig. 3C). En nuestro estudio observamos una disminución significativa en la concentración espermática (Tabla $2, \mathrm{p}<0,05)$, concordando con los resultados de Valiente et al. (2010) y Elangovan et al. (2006) quienes suministraron CP $50 \mathrm{mg} / \mathrm{kg}$ pc por 35 días y CP $200 \mathrm{mg} /$ $\mathrm{kg}$ pc una vez por semana durante 5 semanas, respectivamente.

$\mathrm{Al}$ realizar la histología de los testículos se observó una reducciónen el diámetro de los túbulos seminíferos y en el númerode estratos de células germinales de los ratones tratados con CP, siendo estos resultados similares a los obtenidos por Elangovanet al. (2006), quienes demuestran que una dosis de CP a $200 \mathrm{mg} / \mathrm{kg}$ pc en ratones una vez por semana durante cinco semanas presenta el mismo daño teniendo efectos sobre la espermatogénesis y la fertilidad. Estas observaciones se deberían a los bajos niveles de gonadotropinas y testosterona en el plasma sanguíneo después de la inyección de CP (Means 1975, Chowdhury 1979, Elangovan et al. 2006) concordando con el efecto antiandrogénico que postulamos anteriormente para $\mathrm{CP}$.

Basados en los resultados del presente estudio concluimos que una dosis única de CP $(220 \mathrm{mg} / \mathrm{kg} \mathrm{pc})$ altera la espermiación y permanencia en el epidídimo disminuyendo la concentración y movilidad espermática y a su vez dańa el epitelio seminífero a través de la disminución del diámetro de los túbulos seminíferos y el número de estratos de células germinales de los ratones tratados con CP. Hay que destacar que este es el primer estudio que indica que una sola dosis de $\mathrm{CP}$ en alta concentración causa daño a nivel de la calidad reproductiva y en consecuencia sobre la fertilidad en ratones.

\section{Literatura citada}

Arencibia D.F., L.A. Rosario \& D. Curveco. 2009. Frecuencia espontánea e inducida de anomalías en la morfología de la cabeza del espermatozoide en ratones NMRI. Retel 20(1):2-14.

Barton T.S., A.J. Wyrobek, F.S. Hill, et al. 2003. Numerical Chromosomal Abnormalities in Rat Epididymal Spermatozoa Following Chronic Cyclophosphamide Exposure.Biol. Reprod. 69(4): 1150-7

Bedford J.M. 1979. Evolution of the sperm maturation and sperm storage functions of the epididymis. Baltimore: Urban and Schwarzenberg. pp. 7-21.
Brinkworth M. \& E. Nieschlag. 2000. Association of cyclophosphamide-induced male-mediated, fetal abnormalities with reduced paternal germ-cell apoptosis. Mutat. Res. 447 (2): 149-154.

Charak B., R. Gupta, P. Mandrekar, et al. 1990. Testicular dysfunction after cyclophosphamide-vincristine-procarbazine-prednisolone chemotherapy for advanced Hodgkin's disease. A long-term follow-up study. Cancer 65(9): 1903-1906.

Chowdhury A. 1987. Effect of pharmacological agents on male reproduction.AdvContracept. Deliv. Syst. 3(4): 347-352.

Crook T.R., R.L. Souhami\& A.E. Mclean. 1986. Cytotoxicity, DNA cross-linking, and single strand breaks induced by activated cyclophosphamide and acrolein in human leukemia cells. Cancer Res. 46(10): 5029-5034.

Das U., M. Mallick, J. Debnath, et al. 2002.Protective effect of ascorbic acid on cyclophosphamide-induced testicular gametogenic and androgenic disorders in male rats.Asian J. Androl. 4(3): 201-207.

Elangovan N., T.J. Chiou, W.F. Tzeng, et al. 2006. Cyclophosphamide treatment causes impairment of sperm and its fertilizing ability in mice. Toxicology 222(1-2): 60 - 70.

Ghosh D., U.B. Das, S. Ghosh, et al. 2002. Testicular gametogenic and steroidogenic activities in cyclophosphamide treated rat: a correlative study with testicular oxidative stress. Drug Chem. Tox. 25(3): 281-292.

Hemminki K. \& S. Kallama S. 1986. Reactions of nitrogen mustards with DNA. IARC Sci. Publ. 78: 55-70.

Hoorweg - Nijman J.J., H.A. Delemarre-van de Waal, F.C. de Waal, et al. 1992. Cyclophosphamide-induced disturbance of gonadotropin secretion manifesting testicular damage. Acta Endocrinol. 126(2): 143-148.

Katoh C., S. Kitajima, Y. Saga, et al. 2002. Assessment of quantitative dual-parameter flow cytometric analysis for the evaluation of testicular toxicity using cyclophosphamide and ethinylestradiol treated rats. J. Toxicol. Sci. 27(2): 87-96.

Kenney L., M. Laufer, F. Grant, et al. 2001. High risk of infertility and long term gonadal damage in males treated with high dose cyclophosphamide for sarcoma during childhood. Cancer 91(3): 613-621.

Lahdetie J. 1983. Micronuclei induced during meiosis by ethyl methanesulfonate, cyclophosphamide and dimethylbenzanthracene in male rats. Mutat. Res. 120(4): 257-260.

Lahdetie J. 1988. Induction and survival of micronuclei in rat spermatids.Comparison of two meiotic micronucleus techniques using cyclophosphamide.Mutat. Res. 203(1): 47-53.

Manda K. \& A.L. Bhatia. 2003. Prophylactic action of melatonin against cyclophosphamide-induced oxidative stress in mice. Cell Biol. Toxicol. 19(6): 367-372.

Matsui H., K. Mitsumori, K. Yasuhara, et al. 1995. Morphological evaluation of cyclophosphamide testicular toxicity in rats using quantitative morphometry of spermatogenic cycle stages. J. Toxicol. Sci. 20(4): 407-414.

Means A.R. 1975. Biochemical effects of follicle stimulating hormones on the testis. In: R.O. Greep and E.B. Ashwood, eds. Handbook of Physiology, Section 7, Endocrinology. American Physiological Society, Washington, USA. : 203-219.

Oakberg E.F. 1956. Duration of spermatogenesis in the mouse and timing of stages of the cycle of the seminiferous epithelium. Amer. J. Anat. 99(3): 507-516.

Piña-Guzmán B., M.J. Solís-Heredia, B. Quintanilla-Vega. 2005. Diazinon alters sperm chromatin structure in mice by phosphorylating nuclear protamines. Toxicol. Appl. Pharmacol. 202(2): 189-98.

Poblador M.S., C. Rojas, A. Raya, et al. 1990. The effects of cyclophosphamide on the gonadotrophic cells of the normal rat. Histol.Histopathol. 5(2): 173-80. 
Rezvanfar M., R. Sadrkhanlou, A. Ahmadi, et al. 2008. Protection of cyclophosphamide-induced toxicity in reproductive tract histology, sperm characteristics, and DNA damage by an herbal source; evidence for role of free-radical toxic stress. Hum. Exp. Toxicol. 27: 901-910.

Sotomayor R. \& R. Cumming. 1975. Induction of translocations by cyclophosphamide in different germ-cell stages of male mice cytological characterization and transmission. Mutat. Res. 27(3): 375-388.

Tates A. 1992. Validation studies with the micronucleus test for early spermatids of rats. A tool for detecting clastogenicity of chemicals in differentiating spermatogonia and spermatocytes.Mutagenesis. 7(6): 411-419.

Trasler J.M., B.F. Hales, B. Robaire. 1986. Chronic low dose cyclophosphamide treatment of adult male rats: effect on fertility, pregnancy outcome and progeny. Biol. Reprod. 34(2): 275-283.
Trasler JM., L. Hermo, B. Robaire. 1988. Morphological changes in the testis and epididymis of rats treated with cyclophosphamide: a quantitative approach. Biol. Reprod. 38(2): 463-479.

Trentacoste S.V., A.S. Friedmann, R.T Youker, et al. 2001. Atrazine effects on testosterone levels and androgen-dependent reproductive organs in peripubertal male rats. J. Androl. 22(1):142-8.

Valiente A.M., Y.R. Salgado, N.S Pérez, et al. 2010. Efecto de la ciclofosfamida en la morfología del espermatozoide del raton.Retel 34: 1-24.

World Health Organization (WHO). 2010. Standard procedures. In: T.G. Cooper, eds, Laboratory manual for the Examination and processing of human semen, 5th edn. Switzerland. 